\title{
En torno al cardenal Don Gil Álvarez de Albornoz y el platero sienés Andrea Petrucci: el relicario de la mano de Santa Lucía y el cáliz de San Segundo*
}

\author{
Manuel Parada LóPez De Corselas \\ Università di Bologna / Instituto Catalán de Arqueología Clásica (ICAC) \\ Universidad Complutense de Madrid \\ manu_p186@hotmail.com \\ Almudena Cros Gutiérrez \\ History of Art, Suffolk University \\ almudenacros@gmail.com
}

\begin{abstract}
Resumen
Este artículo trata de la complicada y hasta ahora inédita historia de la llegada a España de dos obras cumbres de la orfebrería sienesa del s. XIV en plata con esmaltes translúcidos: el relicario de la mano de Santa Lucía en la catedral de Toledo y el cáliz de San Segundo en la catedral de Ávila. La importación de estos dos importantísimos objetos devocionales y litúrgicos, ambos firmados por el platero sienés Andrea Petrucci, está relacionada con la estancia en Italia del cardenal don Gil de Albornoz, arzobispo de Toledo y posteriormente cardenal de San Clemente y Santa Sabina y legado papal. El mecenazgo del cardenal castellano y de su círculo en Italia explica la comisión y adquisición de estas piezas, cuyos accidentados itinerarios desembocarían finalmente en Toledo y en Ávila.
\end{abstract}

Palabras clave: Gil de Albornoz, Andrea Petrucci, Santa Lucía, San Segundo, orfebrería medieval sienesa, Ávila, Toledo.

\section{A Discussion on Cardinal Don Gil Álvarez de Albornoz and the Sienese Goldsmith Andrea Petrucci: The Reliquary of St. Lucy and the Chalice of St. Segundo}

\begin{abstract}
This article deals with the complex and hitherto unpublished history of the arrival in Spain of two masterpieces of Sienese craftsmanship in silver and translucent enamel from the fourteenth century: the reliquary of the hand of St. Lucy in Toledo Cathedral and the San Segundo chalice in Ávila Cathedral. The import of these important liturgical and devotional pieces, both signed by the Sienese goldsmith Andrea Petrucci, is inextricably linked with the Italian sojourn of cardinal don Gil de Albornoz, archbishop of Toledo and later cardinal of San Clemente and Sabina, and papal legate. The patronage exercised by the Castilian cardinal and his circle in Italy accounts for the commission and acquisition of these pieces, whose complex itineraries would eventually conclude in Toledo and Ávila.
\end{abstract}

\footnotetext{
* Queremos expresar nuestro más efusivo agradecimiento a los miembros del Departamento de Historia del Arte I (Medieval) de la UCM, así como a los profesores J.M. Cruz Valdovinos y C. Esteras, al Rector del Real Colegio de España, Prof. García-Valdecasas, a su solícita bibliotecaria la dot.ssa Enrica Coser y al canónigo archivero de la catedral de Ávila, D. Justo García.
} 
Key words: Gil de Albornoz, Andrea Petrucci, Saint Lucy, Saint Segundo, Sienese medieval silverwork, Ávila, Toledo.

\section{Don Gil Álvarez de Albornoz (1302-1367): notas sobre su biografía y mecenazgo}

En 1350, el arzobispo de Toledo don Gil Álvarez de Albornoz ${ }^{1}$ viajó a Aviñón para asistir a su reciente promoción al rango de cardenal presbítero de San Clemente. El clérigo de origen conquense ya había visitado la corte papal en 1330 y en $1335^{2}$. Don Gil, que contaba con 48 años de edad cuando fue nombrado cardenal por Clemente VI, había ocupado la cátedra de Toledo desde 1338, a la que renunció tras su promoción cardenalicia. Con anterioridad a su nombramiento como arzobispo, Gil de Albornoz había jugado un destacado papel como consejero y diplomático del rey de Castilla Alfonso XI. En 1334, el entonces arcediano de Calatrava y miembro del Cabildo de la Catedral de Toledo viajó como embajador de Alfonso XI a la corte francesa de Philippe VI con el objetivo de recaudar fondos para la reconquista ${ }^{3}$. Cuatro años más tarde, en 1338, Albornoz se dirigió a Aviñón con motivo de su promoción al arzobispado de Toledo ${ }^{4}$. Allí permaneció durante casi un año, hasta la primavera de 1339, cuando regresó a Castilla con la misión de liderar la cruzada contra los musulmanes en España ${ }^{5}$. En 1342, Albornoz retornó a Aviñón, acompañado del prior de la Orden de San Juan, fray Alfonso Ortiz Calderón, para solicitar asistencia económica ${ }^{6}$. Desde la corte papal de Benedicto XII, el Arzobispo de Toledo marchó a la corte de Philippe VI, donde permaneció durante un año ${ }^{7}$.

1 La biografía más reciente y actualizada en J.G. GARCÍA-VALDECASAS, voz “Álvarez de Albornoz, Gil”, Diccionario Biográfico Español, vol. III, Madrid, 2010, pp. 426-433.

2 En 1330, Albornoz estuvo en Aviñón para resolver una disputa referente a la deuda contraída por su familia y que entorpecía su carrera eclesiástica. A. BOSCOLO, "Documenti aragonesi sulla famiglia Alvarez d'Albornoz", E. VERDERA Y TUELLS (ed.), El Cardenal Albornoz y el Colegio de España, Bolonia, 1972, vol. I, p. 89 (14 de octubre de 1330); J. TRENCHS ODENA, “Albornoz y Aviñón: Relaciones con la Cámara Apostólica (1325-1350)”, E. VERDERA Y TUELLS (ed.), op. cit., 1972, vol. I, p. 269. En 1335, asistió a la coronación de Benedicto XII, vid. E. SÁEZ, J. TRENCHS y C. BAÑARES, "La etapa española de Gil Albornoz (1302-1336)", E. VERDERA Y TUELLS (ed.), op. cit., vol. IV, 1979, nota 90 infra pp. 31-32. Según J.G. GARCÍA-VALDECASAS, op. cit., 2010, p. 426, D. Gil visitó Aviñón en 1327. En general cfr. A. CROS GUTIÉRREZ, The Artistic Patronage of Gil de Albornoz, 1302-1367, a cardinal legate in context, $\mathrm{PhD}$ thesis, University of Warwick, 2008, p. 52.

3 Crónica de Alfonso XI, cl, p. 271 [Crónicas de los Reyes de Castilla: desde Don Alfonso el Sabio hasta los Católicos don Fernando y doña Isabel, ed. C. ROSELL, Madrid, 1953]. Albornoz viajó acompañado de Fernando Sánchez de Valladolid.

4 A. BOSCOLO, op. cit., 1972, p. 84; J. TRENCHS ODENA, op. cit., 1972, pp. 269-270; y J. RIVERA RECIO, Guía de la catedral de Toledo, Toledo, 1949, p. 86.

5 Crónica de Alfonso XI, cxcii, p. 296: "Et en este tiempo veno de Corte de Roma Don Gil Arzobispo de Toledo con la confirmación de su Arzobispado". Sobre los viajes de Albornoz a Avignon, vid. A. CROS GUTIÉRREZ, op. cit., 2008, pp. 52-53.

6 E. SÁEZ, J. TRENCHS y C. BAÑARES, op. cit., 1979, p. 10; y Crónica de Alfonso XI, cclxxiii, p. 347, octubre de 1342.

7 J. GAUTIER DALCHÉ, “À propos d'une mission en France de Gil Albornoz: opérations navales et difficultés financières lors du siège d'Algésiras (1341-1344)", E. VERDERA Y TUELLS (ed.), op. cit., 1972, vol. I, p. 250; Crónica de Alfonso XI, cclxxii, pp. 347 y 367-368. En agosto de 1343, Alfonso XI recibió una 
Gil de Albornoz fue un importante mecenas artístico en Cuenca, Guadalajara, Toledo, Aviñón, Asís y Bolonia ${ }^{8}$. Durante sus legaciones papales en Italia (la primera en 1353-1357 y la segunda en 1358-1367), ordenó la restauración y en algunos casos la construcción de numerosas fortalezas, entre las que destacan las de Ancona, Spoleto y Asís, y el palacio en Cesena. En el testamento que dictó en 1364, dejó provisiones para la donación de objetos litúrgicos y relicarios a las catedrales de Cuenca y Toledo, y estableció la fundación de un colegio residencial para 24 estudiantes en Bolonia (Domus Hispanica o Colegio de España), el cual todavía sigue en funcionamiento y cumple este año de 2014 su 650 aniversario. Asimismo, Gil de Albornoz detalló su voluntad de hacer llegar el relicario de San Blas y su preciada capa pluvial de Opus Anglicanum a la catedral de su ciudad natal, Cuenca9 .

\section{El mecenazgo de D. Gil Álvarez de Albornoz: platería}

2.a. Obras italianas: El relicario de Santa Lucía que se conserva en la Catedral de Toledo es un excelente trabajo de platería y de esmaltes translúcidos de la escuela sienesa. Esta importante pieza, una de las de más alto nivel del Trecento, porta la firma de Andrea Petrucci y de su compañero Giacomo di Tondino, así como la heráldica de Albornoz. Más adelante nos detendremos en su estudio.

2.b. Obras francesas: En la Catedral de Toledo se custodian dos estatuillas-relicario de plata sobredorada que representan a San Ildefonso y San Eugenio. Provenientes

carta de Albornoz en la que anunciaba la concesión de un préstamo del rey de Francia por valor de 50.000 florines, vid. Crónica de Alfonso XI, ccciii, p. 368.

8 En Cuenca, Albornoz donó en su testamento mobiliario litúrgico para la capilla funeraria de su familia en la Catedral. En Guadalajara, Albornoz fundó en 1340 el monasterio agustino de San Blas de Villaviciosa. Vid. A. CROS GUTIÉRREZ, op. cit., 2008, pp. 76-85. En Toledo, Albornoz fundó la Cofradía de la Obra y Fábrica para impulsar los trabajos de la Catedral (ibid., pp. 67-76). Sobre la arquitectura civil y militar de Albornoz, vid. J.M. SANS TRAVÉ, L'attività edilizia militare e civile dell'Albornoz, tesi di laurea inedita, Università degli Studi di Bologna, anno accademico 1972-1973.

9 Testamento original (en latín) en Archivo del Real Colegio de España (ARCE), Archivo Albornociano (AA), IX, 1; traducción al español en J. BENEYTO, El cardenal Albornoz. Hombre de iglesia y de estado en Castilla y en Italia, Madrid, 1986, pp. 294-305. Con respecto al relicario de San Blas y la capa de Opus Anglicanum, el testamento hace observaciones de gran interés: "Item lego a la iglesia de Cuenca la cabeza de plata, de cuarenta y ocho marcos de peso, con las reliquias del bienaventurado San Blas, y mi mejor pluvial, de factura inglesa. Quiero, sin embargo, que esto no pueda ser enajenado, vendido ni empeñado por el deán o el Cabildo, y que se guarde perpetuamente en la sacristía con las demás joyas y reliquias, y que no se sirvan de ello sino en las siguientes festividades: Navidad, Circuncisión, Epifanía, San Blas, Purificación de la Virgen, Anunciación y Resurrección del Señor, Ascensión y Pentecostés, Trinidad, Corpus Christi, San Juan Bautista [¿tendría D. Gil especial devoción también por este santo?], San Pedro y San Pablo, Santa María Magdalena, Ascensión y Natividad de la Virgen, Todos los Santos y San Clemente, así como la Anunciación de Nuestra Señora, que se celebra ocho días antes de Navidad. Quiero igualmente que cuando se celebren los oficios divinos se saque dicha cabeza al altar o se lleve a la procesión, y que el dicho pluvial lo utilice el obispo de Cuenca u otro cualquier obispo que allí celebrase, durante las vísperas, los maitines y la procesión; no habiendo obispo, llévelo el sacerdote que oficie en la misa mayor, pero solamente en la procesión. Asimismo, quiero que se haga una peana o dos ángeles para la dicha cabeza con que se la sustente con decencia, en plata dorada de veinte marcos de peso [...]" (ibid., pp. 297-298). 
de un taller francés, y, aparentemente, con punzón de Aviñón, están decoradas con la heráldica de Albornoz antes de ser promovido al cardenalato en $1350^{10}$.

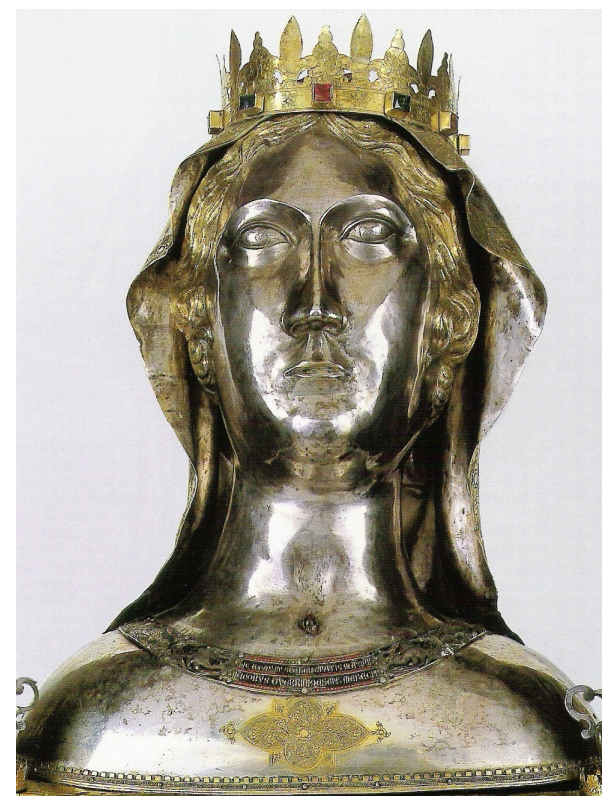

Fig. 1. Busto-relicario de Santa Felicita, firmado por Giacomo di Guerrino y marcado "IA", década de 1340. Montefiascone, Catedral de Santa Margherita.

2.c. Otras obras: El testamento de Gil de Albornoz en 1364 menciona diversas obras de platería sin especificar su origen de producción. Entre estas, aparece una estatuilla de plata sobredorada, de 30 marcos, que representaba a la Virgen María y que destinaba al Convento de San Francisco en Asís ${ }^{11}$. Gil de Albornoz mencionó asimismo un busto relicario de San Blas, de 48 marcos, que donó a la Catedral de Cuenca, pero del cual no ha quedado rastro alguno ${ }^{12}$. Si era de factura francesa o italiana es imposible saberlo, pero quizás estaba influenciado por el busto relicario de Santa Felicita en la Catedral de Montefiascone, el cual Albornoz tuvo ocasión de ver durante su estancia en la ciudad en el invierno de 1353 (Fig. 1) ${ }^{13}$. En 1343, un inventario de la Catedral de To-

10 Sobre el punzón, vid. E. TABURET-DELAHAYE, "L'orfèvrerie au poinçon d'Avignon au XIVe siècle”, Revue de l'Art, 108 (1995), p. 18; y E. TABUERT-DELAHAYE, "Un reliquaire de Saint Jean-Baptiste exécuté par les orfebres siennois Jacopo di Tondino et Andrea Petrucci pour le Cardinal Albornoz", Bollettino d'Arte, suplemento 95 (1996-1998), p. 125; y A. CROS GUTIÉRREZ, op. cit., 2008, pp. 260-264.

11 A. CROS GUTIÉRREZ, op. cit., 2008, pp. 161-162; cfr. J. BENEYTO, op. cit., 1986, p. 300. En la donación a Asís se especifica que se trata de la estatua de la Virgen que estaba en la capilla personal del cardenal Albornoz y se incluyen "tres alfombras grandes mías, es saber, la que compré en Ancona por sesenta ducados y la que fue del señor Albertachio, y otra de las grandes que llevan mis armas".

12 A. CROS GUTIÉRREZ, op. cit., 2008, p. 254; cfr. J. BENEYTO, op. cit., 1986, pp. 297-298.

13 A. CROS GUTIÉRREZ, op. cit., 2008, pp. 121, 254-255; F. FILIPPINI, "La Prima Legazione del Cardinale Albornoz in Italia (1353-1357)", Studi Storici, 5 (1896), pp. 81-120. 
ledo incluyó seis "copetas de plata esmaltadas a las armas del arzobispo don Gil"14. En su testamento, Gil de Albornoz hizo donación de un cáliz sobredorado, de 3 marcos, y una pequeña cruz a la capilla funeraria de su familia (Capilla de los Caballeros) en la Catedral de Cuenca $^{15}$. Al arzobispo de Toledo, para su capilla, dejó cuatro jofainas o bacines de plata de diversa factura, de las cuales dos tenían esmalte central y una tal vez era italiana, ya que le había sido regalada por el arzobispo de Milán ${ }^{16}$.

\section{El platero sienés Andrea Petrucci (activo h. 1338-1367): contexto y producción}
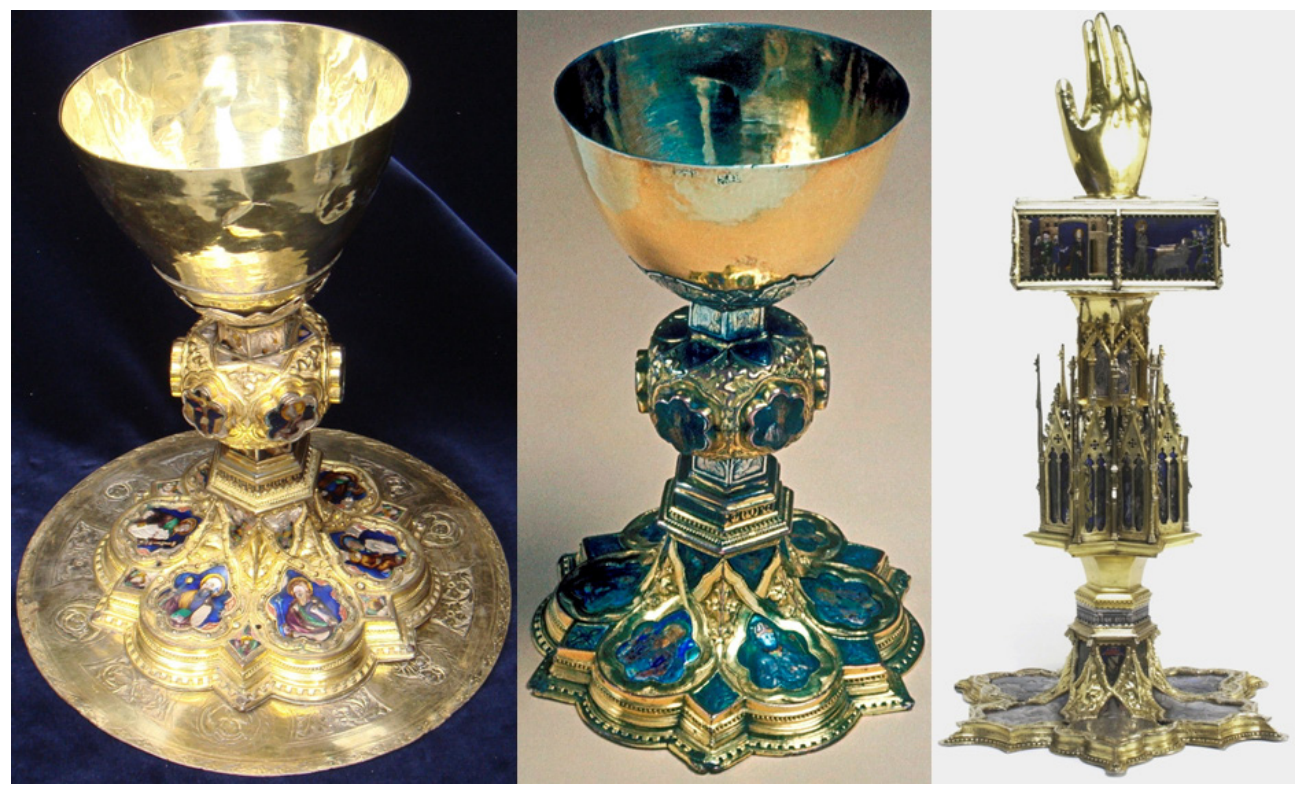

Fig. 2. A la izquierda, patena y cáliz de San Segundo, firmado por Andrea Petrucci, mediados del s. XIV. Ávila, Museo Catedralicio; en el centro, cáliz firmado por Andrea Petrucci, mediados del s. XIV. Cambridge, Fitzwilliam Museum; a la derecha, relicario de la mano de Santa Lucía, firmado por Andrea Petrucci y Giacomo Tondino, h. 1350/1353-1367. Toledo, sacristía de la Catedral.

14 A. CROS GUTIÉRREZ, op. cit., 2008, p. 73. (Archivo de la Catedral de Toledo [ACT], X.12.B.1.2, 2a, fol. 19r).

15 Ibid., p. 237; cfr. J. BENEYTO, op. cit., 1986, p. 297.

16 Cfr. A. CROS GUTIÉRREZ, op. cit., 2008, pp. 238-239. En el testamento se indica "Item, lego al mismo arzobispo de Toledo, para su capilla, dos jofainas de plata, una de ellas dorada, que me dio don Juan, arzobispo de Milán, las cuales entrego en lugar de otras dos doradas que usé en su capilla, una de las cuales me hurtaron en Castilla siendo arzobispo, y la otra ha quedado entre mis bienes. Asimismo, le lego otras dos jofainas blancas, con esmalte en medio, orladas de oro, de doce marcos de peso, en sustitución de otras dos jofainas de plata blanca que hallé en su capilla y se decía que habían sido compradas por don Gutierre, las cuales no encuentro ahora entre mis bienes, acaso porque fueron fundidas" (J. BENEYTO, op. cit., 1986, p. 299). 
Tres son las obras conocidas en las que consta la firma del platero sienés Andrea Petrucci: el cáliz llamado de San Segundo en la Catedral de Ávila -hallado con su patena en dicha ciudad, en la invención de san Segundo (1519), mítico primer obispo de Ávila-, el conservado desde 1904 en el Fitzwilliam Museum de la universidad de Cambridge (Inv. M.24-1904, donación de Frank McClean) y el relicario de la mano de Santa Lucía expuesto en la sacristía de la Catedral de Toledo (Fig. 2). La primera obra ostenta la inscripción "+ANDREA | PETRUC[C]I | ORAFO D|A SIENA | FECE : C|HESTO : CA[LICE]". La del cáliz de Cambridge reza "+ANDRE|A PETRUC|I * DE SE|NIS * ME | FECI[T]". La del relicario conservado en Toledo, "+HOC - OPUS | FECIT • ANDR $\mid$ EAS - PETR $\mid$ UCI • \& IACO|BUS • TONDI|NI • DE SENIS”. Asimismo, se tiene noticia de una pieza más firmada por Andrea Petrucci y de la cual la historiografía no se había apercibido hasta ahora. Se trata de un cáliz que figuró como préstamo en la exposición de 1920 conmemorativa del $50^{\circ}$ aniversario de la fundación del Metropolitan Museum of Art de Nueva York, en cuyo catálogo se recoge como "enameled chalice, Italian (Sienese), XIV century. Signed: Andrea Petrucci"17. La personalidad de este platero ha sido objeto de diversos estudios. Gómez Moreno proponía identificar al artífice del cáliz de San Segundo con Andrea Petri Braccini -activo en Pistoia en 1384-, planteamiento no obstante desestimado por la crítica ${ }^{18}$. Machetti ofrece datos sobre un platero sienés llamado Andrea di Petruccio Campagnini, pero sin identificar obras suyas ${ }^{19}$. Con Toesca y Oman, Andrea Petrucci se dio a conocer en la historiografía internacional, a través de los cálices del Fitzwilliam Museum de Cambridge y de Ávila, aunque es en el estudio de Oman donde se lo identifica con Andrea di Petruccio Campagnini, en base a la contribución documental de Machetti ${ }^{20}$. Martín Ansón recoge la referencia de Machetti, posiblemente conocida a través de Oman; y tanto Cioni Liserani como Taburet-Delahaye reafirman la identifi-

17 The Metropolitan Museum of Art. Fiftieth Anniversary Exhibition. Loans and Special Features, Nueva York, 1920, p. 6 (se indica que la obra se expuso en el ala F, sala 3); "List of Loans Fiftieth Anniversary Exhibition", The Metropolitan Museum of Art Bulletin, XV, 5 (May 1920), p. 114. La referencia es igual de escueta en la reseña sobre dicha exposición en el boletín del Museo, donde tampoco se indica el prestador de la pieza; tanto este como el paradero del cáliz se desconocen por el momento, vid. J. BRECK, "Medieval and Renaissance Decorative Arts and Sculpture", Bulletin of the Metropolitan Museum of Art, XV, 8 (August 1920), p. 180.

18 M. GÓMEZ MORENO, "El cáliz de San Segundo”, Coleccionismo, 109 (enero 1922), p. 3. Ningún otro autor ha vuelto sobre la idea.

19 I. MACHETTI, “Orafi senesi”, La Diana, 4, 1 (1929), pp. 5-109, especialmente pp. 38-39 y 57-104. En la p. 39 Machetti incluye a Andrea Petrucci entre los autores sin obras conocidas.

20 P. TOESCA, Storia dell'arte italiana. II. Il Trecento, Turín, 1951, nota 123 infra p. 897: "Di Andrea Petrucci da Siena è un calice della cattedrale di Avila con smalti su bassorilievo che ricordano Simone Martini e un altro nel Fitzwilliam Museum di Cambridge"; C. OMAN, "Some Sienese Chalices", Apollo, 71 (April 1965), pp. 279-281. El cáliz actualmente en el Fitzwilliam Museum aparece asimismo en A. DU SOMMERARD, Les arts au moyen âge, en ce qui concerne principalement le palais romain de Paris, l'hôtel de Cluny issu de ses ruines et les objets d'art de la collection classée dans cet hotel. Atlas, París, 1846, cap. XIV, pl. III.1; CHRISTIE, MANSON \& WOODS, Catalogue of the Renowned Collection of Works of Art, chiefly formed by the late Hollingworth Magniac, Esq. (Known as the Colworth Collection), Londres, 2-15 July 1892, lot. 798, p. 169; O.M. DALTON, Fitzwilliam Museum McClean Bequest. Catalogue of the mediaeval ivories, enamels, jewellery, gems and miscellaneous objects bequeathed to the Museum by Frank McClean, Cambridge, 1912, n 61, pp. 108-09; Treasures of Cambridge, catálogo de la exposición, Londres, 1959, no 107; R.A. CRICHTON, Cambridge Plate, Cambridge, 1959, p. 13; D.F. ROWE, Enamels the XII 
cación aportada por el mismo Oman ${ }^{21}$. No obstante, Rodríguez Almeida propone -sin apoyo documental- que Andrea Riguardi, compañero de Tondino di Guerrino a partir de 1324, cambiaría su apellido por Petrucci seguramente al morir su padre, un posible Petruccio, hipótesis que Cruz Valdovinos comparte ${ }^{22}$. Cioni hace notar el estado de la cuestión y reafirma las aportaciones de Machetti y Oman, al tiempo que aclara las relaciones entre los Guerrino y Petrucci, estableciendo el parentesco de Tondino di Guerrino, hermano de Giacomo di Gerrino y padre de Giacomo di Tondino. Es este último quien aparece como compañero de Andrea Petrucci en la inscripción del relicario de la mano de Santa Lucía de la Catedral de Toledo ${ }^{23}$. Finalmente, en su minucioso estudio de la pieza con ocasión de su restauración, Pérez Grande apoya la teoría de Cioni Liserani ${ }^{24}$.

El único documento conocido sobre Andrea di Petruccio Campagnini es un contrato fechado el 21 de febrero de 1373 en Siena, el cual trata de la compra de media casa y un huerto por parte de Andrea, mencionando su profesión (aurifex) ${ }^{25}$. Varios

to the XVI Century, a Special Exhibition at The Martin D'Arcy Gallery of Art, Chicago, 1970, n 16; M.M. GAUTHIER, Émaux du Moyen Âge occidental, Friburgo, 1972, p. 225.

21 M.L. MARTÍN ANSÓN, "La importación de obras de esmaltes italianos y su influencia en la Castilla bajomedieval: el llamado «Cáliz de San Segundo»", Archivo Español de Arte, LXVIII, 269 (1995), p. 50; E. CIONI LISERANI, "Per Giacomo di Tondino orafo e smaltista senese", Prospettiva, 83-84 (1996), pp. 56-79; y E. TABURET-DELAHAYE, op. cit. (1996-1998), p. 126. Esta última es explícita: "cet Andrea Petrucci est sans aucun doute, comme l'avait deja reconnu Ch. Oman, le personnage qui apparaît dans les Denunzie di contratti de Sienne pour l'année 1372-1373 sous le nom d'Andrea Petruccio Campagnini”. Sobre Tondino di Guerrino y Andrea Riguardi cfr. E. CIONI LISERANI, "Tondino di Guerrino. Andrea Riguardi", L'art gothique siennois. Enluminure, peinture, orfevrerie, sculpture, catálogo de la exposición, Florencia, 1983, nº 47, pp. 149-150.

22 E. RODRÍGUEZ ALMEIDA, El cáliz de San Segundo de la catedral de Ávila, Ávila, 1997, p. 73; J.M. CRUZ VALDOVINOS, Platería europea en España, (1300-1700), catálogo de la exposición, Madrid, 1997, p. 44. Ese mismo año M. Cátedra, siguiendo el consejo del antropólogo e historiador de la religión William Christian, propuso que Andrea Petrucci pudo pertenecer a la familia de "Florentine Petruccis [(sic.)], tres generaciones de famosos orfebres italianos que viven entre 1397 a 1437 [...] o quizá también proceda del sienés Tore Petrucci quien trabajó entre 1307-1320 en la corte de los Papas de Avignon Clemente V y Juan XXII. Su trabajo pudo entrar en España a través de la catedral de Zaragoza puesto que el Papa Luna envió bastante material a esta ciudad", vid. M. CÁTEDRA, Un santo para una ciudad. Ensayo de antropología urbana, Barcelona, 1997, nota 25 infra pp. 48-49.

23 E. CIONI LISERANI, Scultura e Smalto nell'Oreficeria Senese dei secoli XIII e XIV, Florencia, 1998, nota 107 infra p. 688: "per il Calice [de San Segundo] è stata generalmente proposta una datazione nella seconda metà del Trecento fatta eccezione per i contributi di Emilio Rodríguez Almeida [...] sulla base di argomentazioni che per più motivi non sono in alcun modo condivisibili, e di José Manuel Cruz Valdovinos [...] che ne posticipa la datazione al 1330-1340 senza fornire plausibili motivazioni e condividendo l'ipotesi -assolutamente incomprensible- avanzata da Emilio Rodríguez Almeida [...] di una possibile identificazione dell'orafo Andrea di Petruccio con Andrea Riguardi, socio di Tondino di Guerrino".

24 M. PÉREZ GRANDE, "Estudio histórico-artístico", El relicario de santa Lucía. Restauración, análisis y estudio histórico-artístico [publicación electrónica], Ministerio de Cultura, s.f. (2010), p. 125 (http:// es.calameo.com/read/0000753352eeaca9bdc50, consultado 22/11/2010). Vid. también Archivo Central del IPCE, "Memoria de restauración del relicario de Santa Lucía de la Santa Iglesia Catedral Primada de Toledo", leg. 494, n 4, [restauradores María Paz Navarro Pérez y Manuel Jiménez Villarino, Proyecto Beca de Orfebrería IPCE 2008].

25 Archivio di Stato di Siena (ASS), Gabella Contratti 84, c. 21r, 21 febbraio 1373, vid. E. CIONI LISERANI, op. cit., 1998, nota 96 infra pp. 678-679: "die XXI mensis februarii Andreas olim Petrucci Campagnini, aurifex populi sancti Iohannis, et Bonus olim Iohannis Micchaelis, fornarius olim populi sancti Andree, nomine Marci Iohannis populi sancti Christofori, pro pretio quadraginta quinque florenorum auri 
autores dan muestras de haberse basado en la fecha de este documento para datar hacia 1370-1380, e incluso a finales de siglo, las obras firmadas por Andrea Petrucci ${ }^{26}$. Sin embargo, la data del documento no autoriza al fechado de las obras, ya que en él no se hace mención a la edad ni al estado de la actividad laboral de Petrucci ${ }^{27}$. A falta de documentación sobre la actividad de Petrucci, por el momento solo puede reconstruirse su personalidad artística a través de las obras conservadas y de la relación del relicario de la mano de Santa Lucía con D. Gil de Albornoz, con Giacomo di Tondino y su taller familiar.

\section{Problemática del relicario de la mano de Sta. Lucía y del cáliz de S. Segundo}

Como anticipamos, el relicario de la mano de Santa Lucía de la Catedral de Toledo puede aportar más datos sobre Petrucci y su producción ${ }^{28}$. Su inscripción, en la que firma junto con Giacomo (o Jacopo) Tondino, sugiere una autoría compartida, aunque el hecho de que Andrea Petrucci firme en primer lugar seguramente responda a razones de estatus en el taller o a su mayor jerarquía por experiencia o edad respecto a Tondino. Todo parece indicar que la parte inferior de la obra, con escenas de la vida de San Juan Bautista y el escudo de Gil de Albornoz coronado por el capelo cardenalicio, así como la macolla arquitectónica, pertenecieron a un relicario ideado para contener restos de San Juan Bautista, mientras que la superior, la caja-relicario de Santa Lucía, sería una adición, aunque prácticamente contemporánea. D. Gil de Albornoz, arzobispo de Toledo de 1339 a 1350 y cardenal desde 1350 hasta su muerte

vendiderunt medietatem pro indiviso unius domus et unam petiam terre ortivam positam Senis in populo sancti Mauritii et contrata della Fiera, Bartholomeo olim Fatii Bellarmati populi sancti Petri Castri Veteris de Senis. Die XXI mensis februarii solvit dictus Bartholomeus eidem Bartholomeo camerario, unum florenum et triginta quinque solidos denariorum pro utraque parte ut patet in libro eius Introhitorum folio 23; I florenus, I libra, $X V$ solidi".

26 El caso más llamativo dentro de la bibliografía española lo ofrece M.L. MARTín ANSÓN, op. cit., 1995, p. 48, quien data el cáliz y la patena a fines del s. XIV. No obstante, la cronología más aceptada para dichas obras es de mediados del s. XIV, $c f r$. E. CIONI LISERANI, op. cit., 1998, p. 688; y M. PARADA LÓPEZ DE CORSELAS, "El cáliz 'de San Segundo' de la catedral de Ávila”, Revista de Arqueología, 338 (2009), p. 35.

27 En 1318 aparece otra mención documental de un "Petruccio aurifex". Se trata del registro de bienes propiedad de Duccio di Donato, también platero, y cuya propiedad linda con la de este Petruccio. ASS, "Registro dei beni posseduti nel 1318 da Duccio di Donato", Estimo 118, cc. 1-2., vid. E. CIONI LISERANI, op. cit., 1998, p. 190: "Duccius olim Donati habet unam petiam terre laboratorio positam in curia de Serravalle in loco dicto Mandrie cui ex [uno latere res sunt] heredum Stephani, ex [alio latere ex] fossatus, ex [alio latere res sunt] Mini Cionis et ex [alio latere] Petruccii aurificis; que est per mensuram duorum stariorum et sexagintaquinque tabularum, extimatam in sedecim lib. Et decem sol. Denariorum senensium ut apparet in XLVII libro folio XLIIII'. Cioni Liserani propone que pudiera ser el padre de Andrea di Petruccio Campagnini: E. CIONI LISERANI, op. cit., 1998, p. 693.

28 Sobre el relicario vid. también M. GONZÁLEZ SIMANCAS, Toledo, sus monumentos y el arte ornamental, Madrid, 1929, pp. 145-146; J.F. RIVERA RECIO, La catedral de Toledo, Toledo, 1950, p. 111; J. AINAUD DE LASARTE, Toledo, Barcelona, 1947, p. 114; M. CASAMAR y M.E. GÓMEZ MORENO, "Sacristía", M. REVUELTA RUBINO (dir.), Inventario artístico de Toledo. La Catedral Primada, Madrid, 1989, t. II.1, p. 343; e ibid., "Orfebrería gótica", t. II.2, pp. 290-291. Se aportó por primera vez la lectura correcta de la inscripción en J.M. CRUZ VALDOVINOS, op. cit., 1997, p. 44; E. TABURET-DELAHAYE, op. cit. (1996-1998), pp. 123-136. 
en 1367, permaneció varios días en Siena en 1353 y tuvo una estrecha relación con tal ciudad hasta $1363^{29}$. La presencia de las armas cardenalicias en tres de los esmaltes del pie asignan a la obra la fecha post quem de 1350 (Fig. 3). Basándose en tales noticias Taburet-Delahaye data el objeto suntuario entre 1353 y $1363^{30}$, arco que Cioni Liserani dilata hasta 1367, año de la muerte del prelado. Pérez Grande, por su parte, sugiere que el relicario de Santa Lucía correspondería a una estancia -por el momento no documentada- de Gil de Albornoz en Siena entre 1364 y 1367. La autora reitera que el objeto no figura en el testamento de Gil de Albornoz de 1364, ni en los inventarios del sagrario de Toledo hasta comienzos del s. XVI ${ }^{31}$. Dicho testamento ha de interpretarse críticamente, porque legaba una cabeza-relicario de San Blas de plata a la Catedral de Cuenca, pieza que el cardenal finalmente regaló a Juana I de Nápoles en 1366 según Beneyto, quien se basa en documentos de ejecución testamentaria; Pérez Grande, siguiendo a Beneyto, afirmó que los albaceas del prelado sustituyeron la falta del relicario de San Blas por otro de Santa Lucía, aunque no se ha encontrado explicación a su destino final en Toledo ${ }^{32}$. Es en la tesis doctoral de Almudena Cros Gutiérrez donde se hace por primera vez referencia documental a las peripecias del relicario de Santa Lucía tras la muerte de Gil de Albornoz ${ }^{33}$. El relicario se menciona en el documento de mayo de 1368 en el que los ejecutores testamentarios de Albornoz realizan una declaración (declaratio testamenti) en Bolonia sobre el codicilo (23 de agosto de 1367) que el Cardenal había añadido a su testamento de 1364 poco antes de morir. En la declaratio se refieren al envío de la pieza a Toledo, junto con una cruz con pie esmaltada y varias vestimentas litúrgicas que el cardenal deseaba fueran para el uso de la capilla de San Ildefonso ${ }^{34}$. Este mismo documento explica el paradero del relicario de San Blas, que pesaba 48 marcos y estaba destinado a Cuenca en el testamento de 1364, y que finalmente entregó el Cardenal en vida a la reina Juana de Ná-

29 Sobre los viajes de Albornoz vid. F. LIOTTA y P. NARDI, "Regesti di documenti albornoziani dell'Archivio di Stato di Siena”, E. VERDERA Y TUELLS (ed.), op. cit., 1979, vol. IV, pp. 169-215; S. CLARAMUNT y J. TRENCHS, "Itinerario del cardenal Albornoz en sus legaciones italianas (1353-1367)", E. VERDERA Y TUELLS (ed.), op. cit., 1972, vol. I, pp. 369-432 (p. 375 para las menciones en Siena, del 9 al 20 de octubre de 1353); y J. TRENCHS ODENA, "El itinerario del cardenal Albornoz: nuevos datos", E. VERDERA Y TUELLS (ed.), op. cit., 1979, vol. IV, pp. 38-52.

30 E. TABURET-DELAHAYE, op. cit., 1996-1998, p. 127.

31 M. PÉREZ GRANDE, op. cit., s.f. (2010), pp. 72-73.

32 Sería este el relicario actual de Santa Lucía, según Pérez Grande, adquirido por el cardenal entre 1364 y 1367, es decir, después de redactar el testamento y antes de morir. Ibid., pp. 72-73 y 132. J. BENEYTO, op. cit., 1986, p. 211 cita como fuente ARCE, AA, IX, 5. Existen al menos tres copias manuscritas del documento: ARCE, AA, IX, 6A y 6B; Biblioteca Nacional de España (BNE), Ms. 13023 (Burriel), fols. 70r-72r.

33 A. CROS GUTIÉRREZ, op. cit., 2008, pp. 273-274.

34 Cfr. ibid., pp. 273-274 y 293-295. BNE, Ms. 13023 (Burriel), fol. 70r-v: "Item simili modo ordinamus et declaramus quod ecclesie Toletane prefate dentur et assignentur per dominos supradictos manus sancte Lucie cum capseta et pede de argento de aurato et smaltato secundum quod predictus dominus sabinensis habebat et dorsale predicti domini et capella Alba ac capella India, capella nigra, capella viridis cum omnibus fulcimentis earum et crux magna quondam dicti domini Egidii Cardinalis de argento deaurata et smaltata cum suo pede, eo quod sit erat intentionis predicti domini quod ipse multas reliquias et capellas et similia jocalia a predicta Ecclesiae habuerat et de eis sibi servivit longissimo tempore et multe res ex ipsis in eius manibus perierunt propter quod motus constientia predicta omnia ecclesie supradicte voluit assignari et dari prout certissime nobis constat, volumus tamen quod in festivitatibus predicta Capella sancti Illefonsi predictorum omnium possit habere usum" (copia en ARCE, AA, IX, 5). 
poles. La catedral conquense fue compensada con la donación de una caja-relicario dorada, de 36 marcos de peso, aunque no se precisa a qué santo estaba dedicada ${ }^{35}$. Desde luego, no se especifica que tuviera esmaltes, como es el caso del relicario de Santa Lucía, y se ignora su paradero. Entre los firmantes de la citada declaración de 1368 figura Alfonso de Toledo, sobre el que luego volveremos ${ }^{36}$.

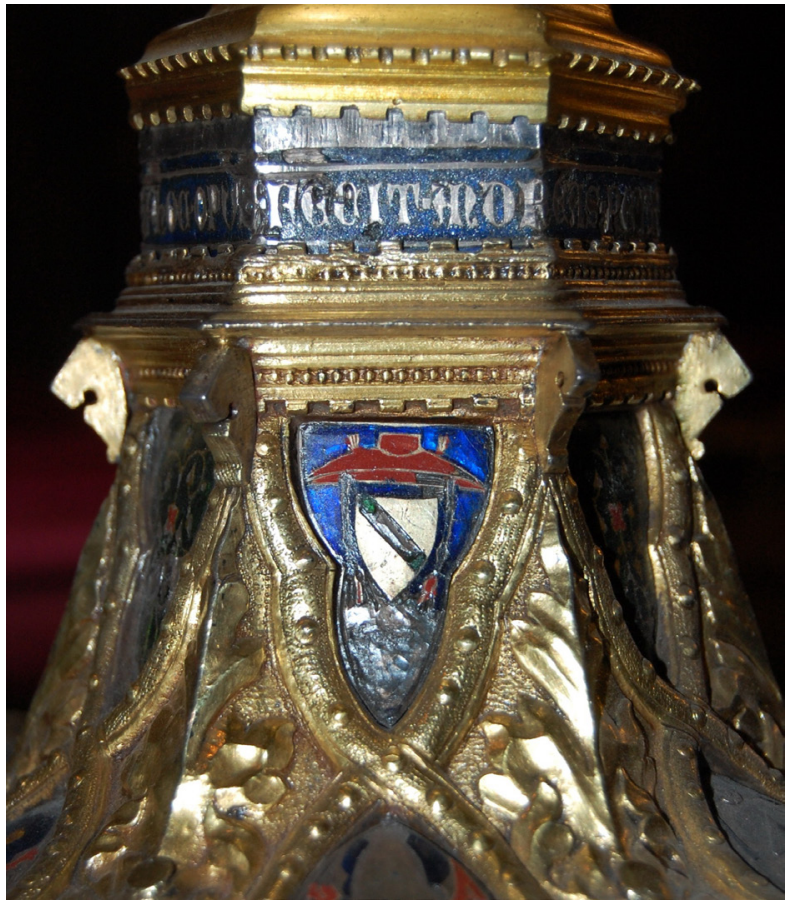

Fig. 3. Detalle del relicario de la mano de Santa Lucía, con el escudo de D. Gil de Albornoz y parte de la inscripción, con el inicio del nombre de Andrea Petrucci.

En septiembre de 1371, el relicario de Santa Lucía está documentado en relación con la Catedral de Toledo. Aunque el documento/declaratio de 1368 especificaba la

35 BNE, Ms. 13023 (Burriel), fols. 71v-72r: "Item simili modo ordenamus et declaramus quod Ecclesie Conchensi prefate dentur et asignentur per dominos supradictos una Capseta de aurata cum uno reliquiario deaurato ponderis triginta sex marcarum et sex unciarum. Et pars quam reverendissimus in christo pater et dominus dominus Anglicus miseratione divina eps. Albanensis ac terrarum Ecclesie in Italia consistentium vicarius generalis dimiserit de brachio sancte Lucie quod executione predicti domini sabinensis accepit in rencompensatione capitis argenti cum reliquiis beati Blasii ponderis quadraginta octo marcharum quod predictus dominus eidem ecclesie in suo testamento legabat et pedis seu angelorum quos pro sustentatione predicti capitis fieri mandaba ponderis viginti marcharum argenti quos quidem caput et angelos ecclesia predicta non habuit quia predictus dominus sabinensis in vita sua dederat caput domine regine sicilie sed isto modo voluit predite ecclesie satisfieri volumus tamen quod predicta omnia dentur predicte Ecclesie cum pactis et conditionibus per dictum dominum factis in suo testamento circa legationem predicti Capitis". Vid. también ARCE, AA, IX, doc. 6B, fols. 20-21.

36 Ibid., fol. 65r: "venerabilis dominus Alfonsus fernandi de Toleto archidiaconus valentinus". 
capilla de San Ildefonso como lugar de depósito del objeto precioso, una bula papal ofrecía una generosa indulgencia a los visitantes de la capilla de Santa Lucía, "a la cual el Cardenal de Sabina Gil [de Albornoz] donó un relicario con reliquias de esta santa, debido a su gran devoción [a santa Lucía]" ${ }^{37}$. Sin embargo, esta supuesta devoción de don Gil a Santa Lucía no está documentada en ninguna donación, instrucción o fundación, y quizás era una simple excusa que interesaría a los albaceas y que también beneficiaría a dicha capilla de la Catedral; la bula no informa sobre cuándo se realizó la donación -en realidad, decidida por los albaceas en la declaratio- ni si ya se había efectuado el envío a Toledo, por lo tanto puede ser anterior o posterior a la llegada del relicario. En 1372, en el arbitraje sobre la administración de Fernando Álvarez de Albornoz, el Colegio de España hizo patente su descontento porque el relicario de Santa Lucía ("el brazo de Santa Lucía en una cubierta de plata"), junto con una capa pluvial y algunas perlas se habían enviado fuera del Colegio sin su autorización ${ }^{38}$. Así pues, el relicario y la capa pluvial -seguramente la misma que don Gil de Albornoz donaba a la Catedral de Cuenca en su testamento-, habían estado en el Colegio al menos a la llegada de los primeros colegiales en 1368-1369. Posiblemente transfirió tales objetos a la Catedral de Toledo Fernando Álvarez de Albornoz, el cual había enviado allí parte de los libros de su tío don Gil desde el Colegio ${ }^{39}$. Le ayudó el mismo Alfonso que figura en el documento de 1368, nombrado sucesivamente arcediano de Toledo y obispo de Ávila, y que tuvo un papel fundamental en la obtención de preciados objetos y reliquias para la Catedral de Toledo procedentes de la ejecución del testamento de don Gil ${ }^{40}$. El episcopologio abulense en el s. XIV es confuso; al parecer hubo varios obispos llamados Alfonso o Alonso, al menos tres

37 A.-M. HAYEZ (ed.), Grégoire XI (1370-1378): lettres communes analysées d'après les registres dits d'Avignon et du Vatican, Roma, 1992-1996, no 10695: "Omnibus vere penitentibus et confessis qui capellam s. Lucie sitam in eccl. Toletan., ad quam b. m. Egidius, episc. Sabinen., singularem habebat devotionem et ob devotionem eidem capelle unum reliquiarium cum reliquiis ejusdem b. Lucie donavit, in consuetis et b. Lucie ad dicte capelle dedicationis festivitatibus visitaverint, conceditur indulgentia de uno anno et 40 diebus, octavis vero et diebus, de 100 diebus, presentibus post 20 an. minime valituris".

38 B.M. MARTI, “1372: The Spanish College versus the Executors of Cardinal Albornoz's Testament”, E. VERDERA Y TUELLS (ed.), op. cit., vol. II, 1972, p. 107: “Item quare fuit datum unum pluviale et certe perle et brachium Sancte Lucie de argento", tomado de Archivio di Stato di Bologna, Demaniale, Collegio di Spagna, busta 3/ 7872, doc. 92 (copia en ARCE, AA, IX, 28). En ARCE, AA, IX, 28, fol. 2 se cita a "Alfonsum Ferdinandi de Toleto archidiaconum toletanum et olim camerarium". El documento recoge el arbitraje entre el Colegio de España en Bolonia y los dos representantes de los albaceas de D. Gil de Albornoz, que fueron su sobrino Fernando Álvarez de Albornoz, ya arzobispo de Sevilla (nombrado por Gregorio XI el 9 de junio de 1371), y Alfonso Fernández de Toledo, sobre los que volveremos más adelante por su papel clave en la llegada a Castilla de objetos suntuarios.

39 A. CROS GUTIÉRREZ, op. cit., 2008, pp. 274-275. La queja principal del Colegio se refiere a la gestión de la institución por Fernando Álvarez de Albornoz y a la venta de libros pertenecientes a la misma. Se compensó al Colegio con una fuerte suma de dinero y se admitió que la capa y el relicario se habían sacado lícitamente, mientras que las perlas ya se habían devuelto. Cfr. B.M. MARTI, op. cit., 1972, pp. 114 y 121. En relación con el relicario, recordemos que la bula papal que legitima su presencia en Toledo fue emitida por Gregorio XI, quien antes que papa había sido nombrado albacea de don Gil, este hecho y la explicación contenida en la declaratio convencieron sin duda a los juristas mediadores del arbitraje.

40 El papel del obispo de Ávila se reconoce en el Libro Obituario de la Catedral de Toledo. ACT, Ms. 42-31, fol. 49v, Junio: "Missa de sancta M. por don Alfonso Obispo de Avila que ordeno el Cabillo.por los ornamentos et joyas et reliquias que procuro et traxo para esta eglesia dela execucion del Cardenal don Gil. et salen con Responso sobre la sepultura del dicho Cardenal”, vid. A. CROS GUTIÉRREZ, op. cit., 2008 , p. 296. 
y en fechas muy próximas. Tras cotejar algunas fuentes del periodo sugerimos que nuestro personaje se tratase de [Pedro (?)] Alfonso Fernández de Toledo, camarero (cubiculario) y uno de los ejecutores testamentarios de D. Gil de Albornoz, en su caso tanto para los asuntos de Italia como para los de España ${ }^{41}$. Fue también tesorero (al menos desde la redacción del testamento de don Gil en 1364) y arcediano de la Catedral de Toledo (sucediendo en el cargo a Fernando Álvarez de Albornoz), entre otros cargos en distintas diócesis, y finalmente obispo de Ávila (1372-1378) ${ }^{42}$, sede en la cual ya Inocencio VI le había concedido una canonjía el 20 de marzo de $1354^{43}$. Como procurador de don Gil, Alfonso consignó a los dominicos de Bolonia 36 libros del prelado para que los custodiaran temporalmente, en presencia de Fernando Álvarez de Albornoz, el 6 de abril de $1365^{44}$. Ambos hombres de confianza del Cardenal son los responsables de la compra de terrenos y la erección del Colegio de España (1365-1367), y tenían permiso para redactar sus estatutos en 1368 (desconocidos), aunque a principios de 1369 renunciaron a la administración y gobierno de la institución albornociana ${ }^{45}$; pese a ello, Fernando comparece como procurador del Colegio

41 En el testamento se declara "nombro mis albaceas [...], y subordinados a ellos, y para las cosas que se han de hacer aquí en Italia a [...] Alfonso Fernández, tesorero de la iglesia de Toledo, mi camarero sobredicho; y para las cosas que se han de hacer en España [...] a mi dicho camarero [...] a los cuales instituyo por mis ejecutores, dándoles entera y libre potestad de ejecutar y de cumplir con mis bienes todas y cada una de las cosas contenidas en este testamento" (J. BENEYTO, op. cit., p. 304).

42 Sobre este personaje $c f r$. V. BELTRÁN DE HEREDIA, Cartulario de la Universidad de Salamanca (1218-1600), Salamanca, 1970, vol. 1, pp. 126, 158 y 160; E. SÁEZ y J. TRENCHS ODENA, Diplomatario del cardenal Gil de Albornoz: Cancillería Pontificia (1351-1353), Barcelona, 1976, docs. 76-78 y 383385; E. SÁEZ, M.T. FERRER y J. TRENCHS ODENA, Diplomatario del cardenal Gil de Albornoz: Cancillería Pontificia (1354-1356), Barcelona, 1981, docs. 52-54; M.T. FERRER y R. SÁINZ DE LA MAZA, Diplomatario del cardenal Gil de Albornoz: Cancillería Pontificia (1357-1359), Barcelona, 1995, docs. 71 y 108; T. SOBRINO CHOMÓN, "La restauración de la diócesis. Sucesión episcopal", G. DEL SER QUIJANO (ed.), Historia de Ávila. III. Edad Media (siglos XIV-XV), Ávila, 2006, p. 424; y S. CABALLERO ESCAMILLA, La escultura gótica funeraria de la catedral de Ávila, Ávila, 2007, pp. 185-186. BNE, Ms. 13023 (Burriel), fol. 59v, menciona a "Don Alphonso obispo que fue de Ávila y de Palencia y arcediano de la obra de la iglesia de Toledo" entre los ejecutores del testamento del cardenal Albornoz en un documento datado 13 noviembre 1387. ¿Tendría algo que ver con Alfonso Fernández de Toledo o de Vargas?

43 E. SÁEZ, M.T. FERRER y J. TRENCHS ODENA, op. cit., 1981, doc. 53: "Inocencio VI concede a Pedro Alfonso, clérigo de Toledo y cubiculario del cardenal Albornoz, una canonjía en la catedral de Ávila y, 'sub expectatione', una prebenda con prestimonios y porciones prestimoniales en la misma catedral, a pesar de que ya posee una porción en la catedral de Toledo y un beneficio sin cura, 'de los siervos', en la iglesia de Ciudad Real y, 'sub expectatione', una canonjía y prebenda en la catedral de Barcelona”.

44 A. GARCÍA Y GARCÍA y C. PIANA, "Los manuscritos filosófico-teológicos, históricos y científicos del Real Colegio de España de Bolonia”, Salmanticensis, 14 (1967), p. 82.

45 A. PÉREZ MARTÍN, Proles Aegidiana I (Studia Albornotiana, XXXI), Bolonia, 1979, pp. 16-19. Sobre todo este proceso de fundación del Colegio y redacción de sus estatutos (los primeros hechos públicos, en 1377, son los redactados y revisados por Pedro, obispo de Cuenca), vid. B. MARTI, The Spanish College at Bologna in the Fourteenth Century. Edition and Translation of Its Statutes, with Introduction and Notes, Philadelphia, 1966, pp. 16 y ss. Cuando, en su testamento, Gil de Albornoz instituye el Colegio de España y lo declara su heredero universal, señala asimismo: "Item quiero y ordeno que los sobredichos Fernando Álvarez, abad de Valladolid, y Alfonso Fernández, mi camarero, y cada uno de ellos, tengan cuidado de vigilar la construcción de la sobredicha casa o colegio y capilla, y de comprar las posesiones y rentas que sean necesarias para la sustentación de los dichos veinticuatro colegiales y dos capellanes; y les mando y ruego con cuanta fuerza puedo, que residan en Bolonia después de mi muerte al menos durante dos años continuos, para cumplir las cosas sobredichas. Y por sus gastos y trabajos les lego a cada uno seiscientos florines, además de los sobredichos que, como de mi comitiva, deberán recibir" (J. BENEYTO, op. cit., 1986, p. 204). En el 
en la documentación relativa a compras y transacciones hasta al menos agosto de $1371^{46}$. Su compañero Alfonso estaba ausente en el arbitraje de mayo de 1372; se ha sugerido que marchó de Bolonia rumbo a Castilla ese año, en el que fue nombrado obispo de Ávila, dejando el Colegio, donde tenía derecho a residir ${ }^{47}$. Lo hizo precisamente el mismo año -aunque no sabemos si en el mismo momento- en que Fernando también regresó a España -este último, en septiembre de 1372, acompañando a los restos de don Gil, que serían sepultados en la capilla de San Ildefonso de la Catedral de Toledo- y en el que se produjo la citada disputa y arbitraje con el Colegio; resulta lógico por consiguiente que tanto Fernando como Alfonso, ejecutores del testamento de 1364, con intervención directa en las modificaciones de 1368 y responsables del Colegio de España en el periodo 1364-principios 1369, se encargaran del envío a Toledo entre 1369 y 1372 de los preciosos objetos comentados. Ya hemos indicado que la bula de septiembre de 1371 podría ser anterior o posterior a la llegada del relicario a Toledo; de todas formas, como Alfonso Fernández estaba ausente del arbitraje realizado en Bolonia en mayo de 1372, pudo haber sido él quien llevase personalmente la pieza desde Italia a Castilla en esas fechas, como por otro lado hace pensar la mención en el obituario citada arriba. Es interesante que poco después, en 1375, el obispo Alfonso fundara el monasterio jerónimo de Guisando, habitado por "eremitas", curiosamente italianos $^{48}$. Su sepulcro, en la capilla de San Ildefonso de la Catedral

contrato para la construcción del Colegio (5 de abril de 1365) figuran de parte de dicha institución Fernando Álvarez de Albornoz, abad de Valladolid, y Alfonso Fernández, tesorero toledano (cfr. transcripción en A. SERRA DESFILIS, Matteo Gattapone, arquitecto del Colegio de España, Bolonia, 1992, p. 197). La labor de Alfonso, camarero de D. Gil de Albornoz, se registra también en la documentación del Colegio: el 6 de julio de 1368 entrega vestiduras a un colegial (ARCE, Libri rationum, reg. 3, c. 72r); el 23 de noviembre interviene en la realización de las vidrieras de la capilla (ibid., c. 70v) y el 10 de diciembre realiza una visitación al Colegio, denominado "palatium", acompañado del arcediano de Toledo (ibid., c. 22r), que en ese momento sería aún Fernando Álvarez de Albornoz. Alfonso puede ser el personaje representado con hábito azul y mitra en la miniatura de: Biblioteca del Real Colegio de España, Cod. 214, fol. 1r (entrega de los estatutos redactados por Pedro de Cuenca). Otros documentos sobre compras de terrenos y casas para el Colegio en R. GONZÁLVEZ, "E1 Ms. 43-1 de la Catedral de Toledo. Un registro de documentos de Fernando Álvarez de Albornoz (13601371)", E. VERDERA Y TUELLS, op. cit., 1972, vol. II, pp. 167-207; se cita a Alfonso Fernández de Toledo en los docs. 123-125, 127-129, 131, 133, 135, 137. Alfonso Fernández, con título de arcediano valentino, figura en un recibo de 18 de diciembre de 1367 como responsable de dar la orden de pago de 500 florines de oro a favor de Matteo Gattapone por las reparaciones, pinturas y adornos de la capilla donde se sepultó a D. Gil en San Francisco de Asís (capilla de Santa Catalina), vid. AA, IX, 13.

46 R. GONZÁLVEZ, op. cit., 1972, pp. 176-202.

47 Según los estatutos de 1377, solamente se podía dar hospedaje en el Colegio a los miembros de la casa de Albornoz y se añade la excepción de Pedro, obispo de Cuenca, y Alfonso, obispo de Ávila, según se indica, debido a su relación con el cardenal fundador y los servicios prestados al Colegio, cfr. B. MARTI, op. cit., 1966, pp. 290-291.

48 J. TELlO MARTíneZ, Cathálogo sagrado de los obispos... de Ávila (1788), Ávila, 2001, p. 163; T. SOBRINO CHOMÓN, op. cit., 2006, p. 424; y F. DE LAS HERAS FERNÁNDEZ, Los Obispos de Ávila. Su acción pastoral en el ambiente histórico de su tiempo a partir de la predicación apostólica, Ávila, 2004, p. 109. Según Ariz este obispo "dio de limosna a su Iglesia, tres mil maravedís de renta, situados en la Martiniega, para un aniversario que se haze por los Reyes, en tres de mayo. Y manda el Rey que los paguen de lo que le pagan los judios a su Alteza, y assi dice el Privilegio. Qui donatus triamilia in Martiniega, año 1378. Enterrose en la Capilla de san Ildefonso, tiene un bulto muy bien obrado, junto al altar desta Capilla con aniversario, en 7 de mayo", vid. L. ARIZ, Historia de las Grandezas de la Ciudad de Ávila, Alcalá de Henares, 1607 (ed. facsímil, Ávila, 1978), pp. 80-81. Para esta fundación de Guisando, ¿habría sido importante la experiencia previa de Alfonso en la construcción y organización del Colegio de España? En el s. XVI, algunos monjes del 
de Ávila (Fig. 4), tal vez exento en origen, de taller toledano, con rica decoración vegetal y escudos cuartelados hasta ahora no identificados satisfactoriamente ${ }^{49}$, fue remodelado a finales del s. XV, después de que Alonso González de Valderrábano "el deán Gordo" adquiriese y refundase la capilla (1465); la sepultura se empotraría en el muro y se añadiría la inscripción que luce actualmente, "Don Alonso el Segundo deste nombre obispo de Avila", aunque este prelado sería en realidad al menos el tercer obispo de Ávila con dicho nombre. La capilla de San Ildefonso se ubica muy cerca de la de San Blas, donde estuvo enterrado Sancho Blázquez Dávila; ambas pudieron verse afectadas por las obras llevadas a cabo en época del obispo Alonso Carrillo de Albornoz entre 1498 y $1500^{50}$. Todo ello puede dar pie a nuevas hipótesis sobre la invención de San Segundo y las peripecias de su cáliz ${ }^{51}$. Tal vez el obispo Alfonso sea el responsable de la llegada de dicha obra a la Catedral de Ávila, hipótesis alternativa a las propuestas de Sancho Blázquez Dávila (obispo de Ávila entre 1312 y su muerte en 1355/56) -formulada por Rodríguez Almeida- o el cardenal Juan de Cervantes (obispo de Ávila entre 1436/37 y su traslado a Sevilla en 1448/49) -por Martín Ansón- ${ }^{52}$. En relación con la posible comitencia albornociana del cáliz de San Segundo, recordemos además que prácticamente todos los santos representados en sus esmaltes portan libros, lo cual invita a pensar que esta pieza se hizo para un contexto académico, posiblemente el Colegio de España, de la misma manera que sucede con la pala de altar de Marco Zoppo encargada por dicha institución.

El relicario de Toledo no solamente aporta la inscripción que menciona a sus artífices. En el interior del pie figura 6 veces una de las primeras marcas sienesas conocidas, consistente en las letras "IA" ${ }^{53}$. Antes que en esta pieza, como señala Cioni Liserani, la misma marca se estampó en el busto-relicario de Santa Felicita, obra de Giacomo di Guerrino, tío de Giacomo di Tondino - compañero de Andrea Petrucciy a su vez hermano de Tondino di Guerrino - compañero de Andrea Riguardi-, todos

monasterio Guisando, hoy en ruinas, acabarían teniendo un peso importante en otro de los hitos hispánicos: la fundación del monasterio de San Lorenzo de El Escorial.

49 El frontal del sepulcro porta siete escudos cuartelados. En el campo del primer y cuarto cuartel un castillo. En el segundo y tercer cuartel cinco estrellas colocadas en sotuer. Quizás se puedan identificar con la heráldica de Carrillo Rojas. Agradecemos a Carlos Nieto sus indicaciones heráldicas.

50 Sobre el sepulcro vid. E. RUIZ AYÚCAR, Sepulcros artísticos de Ávila (Pequeña historia local), Ávila, 1985, p. 69; S. CABALLERO ESCAMILLA, op. cit. 2007, pp. 186-188. Sobre las obras de las capillas mencionadas, vid. además C. ABAD CASTRO, "El obispo Sancho Blázquez Dávila (1312-1355) y la capilla de San Blas en la catedral abulense", M.L. MELERO MONEO et al. (eds.), Imágenes y promotores en el arte medieval. Miscelánea en homenaje a Joaquín Yarza Luaces, Bellaterra, 2001, pp. 245-254.

51 En esta ocasión no podemos detenernos en tales circunstancias. Remitimos a M. PARADA LÓPEZ DE CORSELAS, "El cáliz 'de san Segundo' entre la realidad y el mito: avatares de un camino de santidad", ArqueoUCA, 2 (2012), pp. 109-123.

52 Sobre tales teorías de la llegada del cáliz a Ávila y la invención de san Segundo cfr. ibid.

53 La restauración del relicario en el IPCE, entre otros pormenores técnicos, como la valiosa barra de plata que sirve para fijar la caja al resto de la obra (la riqueza de dicha barra sorprende, sobre todo teniendo en cuenta que no es visible a no ser que se desmonte el relicario), ha concretado el número de marcas y su ubicación en la obra, vid. Archivo Central del IPCE, op. cit., pp. 13-14. M. PÉREZ GRANDE, op. cit., s.f. (2010), pp. 130-131, plantea que las marcas serían una manera de garantizar que cada uno de los esmaltes del pie estaban hechos sobre la lámina de plata requerida; asimismo, hace notar la presencia de una posible "burilada" para controlar la calidad del material. 


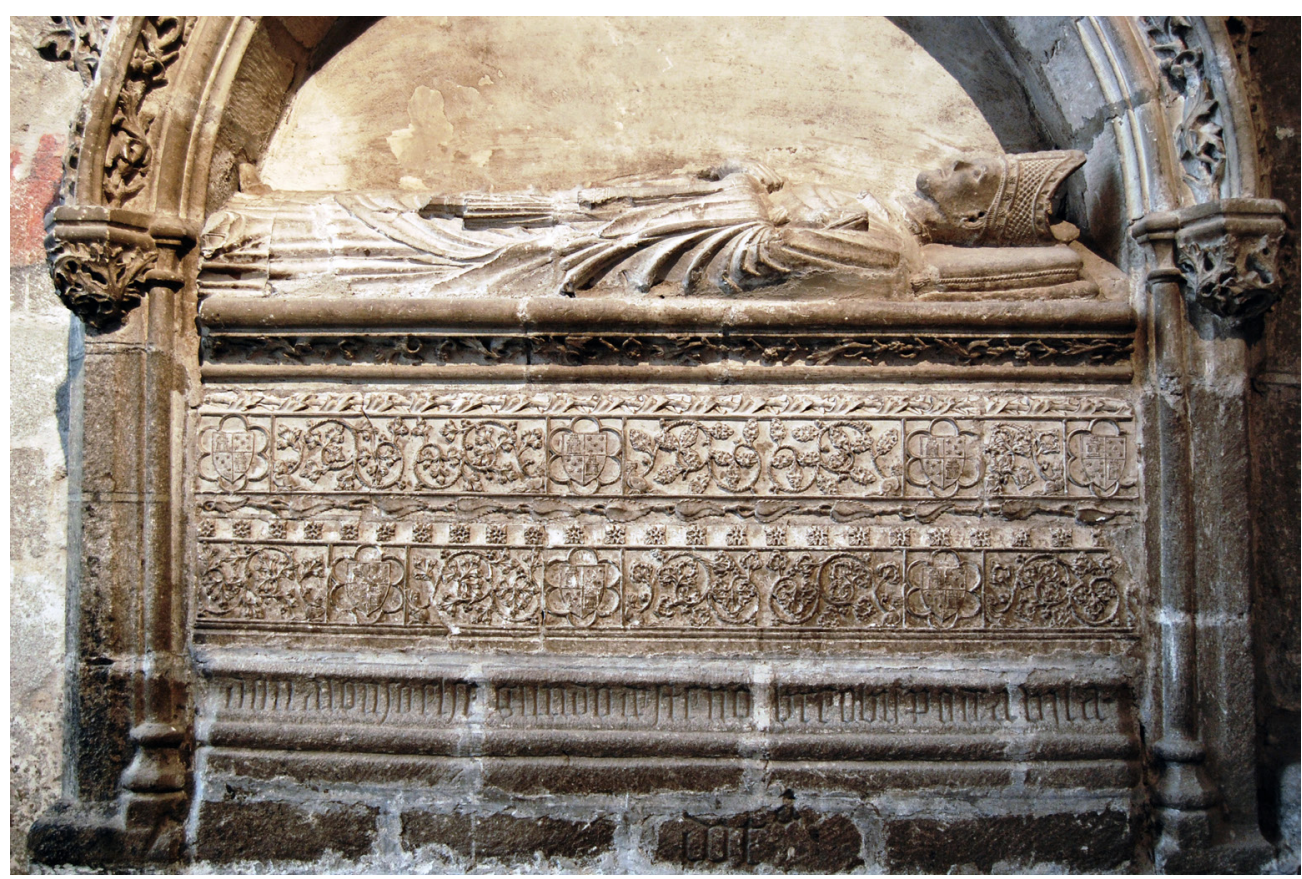

Fig. 4. Sepulcro del supuesto Alfonso II, obispo de Ávila. Catedral de Ávila, capilla de San Ildefonso.

ellos, prestigiosos artífices de la escuela sienesa ${ }^{54}$. Piensa la autora que el punzón pertenecería al tío y tarde o temprano lo heredaría el sobrino; en la marca se utilizaría el comienzo del nombre latino del tío, que coincide también con el de su sobrino, Iacobus ${ }^{55}$. También es plausible que la "IA" aluda a otra variante del mismo nombre, Iachomo. A esta marca, que relaciona la estructura del relicario de Toledo con el taller de Giacomo di Guerrino, se suma la rica gama cromática empleada en los esmaltes, que remite al mismo taller, de donde muy posiblemente proceden ${ }^{56}$. A falta de mayores precisiones documentales no se puede concretar si Andrea Petrucci fue platero propiamente dicho, únicamente esmaltador, o si desarrolló ambas actividades indistintamente. Cabe argüir que dicho artífice estaba lo suficientemente reconocido como para firmar en el encargo del cardenal Gil de Albornoz, obra verdaderamente excepcional. Como se acaba de exponer, la formación de Petrucci depende con gran seguridad del taller familiar de Giacomo di Tondino, de donde proceden también los colores empleados en el cáliz

54 Sobre la importante saga de los Guerrino y su taller vid. E. CIONI LISERANI, op. cit., 1998, pp. 265362 y $624-706$.

55 Ibid., pp. 656 y ss.; J.M. CRUZ VALDOVINOS, op. cit., 1997, p. 44, propone que tal marca corresponde a la "A" de "Andreas" - Andrea Riguardi que, recuérdese, Cruz identifica con Petrucci- y a la "I" de "Iacobus" -Giacomo di Tondino- unidas. Esta última hipótesis es difícilmente confirmable si tenemos en cuenta la presencia de la misma marca en el busto-relicario de Santa Felicita.

56 E. CIONI LISERANI, op. cit., 1998, p. 687. 
de Ávila ${ }^{57}$. Es posible que fuera de mayor edad que Giacomo di Tondino. Quizás por ello Andrea firma en primer lugar, hecho que también podría deberse a la autonomía de ambos como maestros reconocidos que firman el relicario en colaboración. Como sugiere Cioni Liserani, el cáliz de la Martin D’Arcy, obra de Giacomo di Guerrino, con su recuperación del perlinado general y con la novedosa utilización del pie con moldura dentada, pudo servir de modelo para el cáliz de Ávila y el cáliz nº 237-1874 del Victoria and Albert Museum, firmado por el "frate Iachomo Tondusi de Sena" y que merece un estudio detallado ${ }^{58}$. Se ha sugerido identificar a este fraile con Giacomo di Tondino, el mismo colaborador de Andrea Petrucci ${ }^{59}$. El religioso es autor también del relicario del Museo di Palazzo Venezia en Roma, con pie de planta mixtilínea muy semejante al del relicario de Toledo ${ }^{60}$. Pensamos además que Petrucci guarda alguna relación con el grupo de artífices responsables del relicario del Corporal de Bolsena de la Catedral de Orvieto (Fig. 5), firmado en 1338 por Ugolino di Vieri y socios. Lleva a esta idea el San Andrés del cáliz de San Segundo, que reproduce invertidos el esquema del busto y los rasgos faciales fundamentales de un profeta del remate central de la cara posterior del mencionado relicario ${ }^{61}$. Además, en el cáliz de Ávila se emplean motivos que recuerdan la parte superior de la misma obra, como el botón dorado entre hojas verdes -en la parte superior del nudo del cáliz-y la coloración de las alas de los ángeles -en los querubines del pie del cáliz-. Han de destacarse las similitudes entre las arquitecturas -y también algunos motivos vegetales- del relicario de Orvieto y las escenas del pie del relicario de Toledo y la Anunciación de la patena del círculo de Ugolino di Vieri conservada en la Galleria Nazionale dell'Umbria en Perugia, semejanzas expuestas por Pérez Grande y que compartimos ${ }^{62}$. El relicario de Orvieto no solamente es importante desde el punto de vista artístico, sino también histórico, ya que sin duda D. Gil de Albornoz lo conoció en sus visitas a la ciudad, del mismo modo que conocería el busto-relicario de Montefiascone, ciudad donde el cardenal sufrió un largo y penoso sitio que acabaría superan-

57 M. PÉREZ GRANDE, op. cit., s.f. (2010), p. 130, plantea la siguiente hipótesis: “Gil de Albornoz no acudió a un obrador cualquiera para hacer su encargo. Si Giacomo di Guerrino había sucedido a su afamado hermano y mantuvo alta la reputación del obrador familiar con sus propios méritos, parece probable que el prelado español se dirigiera a él, y que Guerrino asignara la ejecución de la obra a dos de los artífices que trabajaban bajo su dirección, uno de ellos su propio sobrino".

58 E. CIONI LISERANI, op. cit., 1998, pp. 625 y ss., especialmente p. 635.

59 E. TABURET-DELAHAYE, op. cit., 1996-1998, p. 132; E. CIONI LISERANI, op. cit., 1998, p. 673. E. RODRÍGUEZ ALMEIDA, op. cit., 1997, pp. 36 y 69, detecta una serie de arquillos en el hombro de la dalmática de un santo figurado en el cáliz del Victoria and Albert, que se repiten en el sepulcro de la patena de Ávila.

60 A su vez, ambos pies son la evolución de modelos como el del relicario del Musée de Cluny de París (Cl. 9190) datado por inscripción en 1331, vinculable con el círculo de Tondino di Guerrino y Andrea Riguardi. Este relicario también se relaciona con el de Toledo por los esmaltes vegetales de su astil.

61 La copia se evidencia especialmente en las dos líneas verticales que corresponderían a los laterales de la diadema del profeta. La diadema no tendría sentido en san Andrés, pero Petrucci repitió sus incisiones laterales, que luego reaprovechó para trazar en la cabellera del santo unos forzados mechones hacia arriba que rompen con la armonía del peinado. El hecho de que la copia esté invertida podría sugerir el uso de algún tipo de plantilla o modelo del taller. Estos datos se aportan por primera vez en M. PARADA LÓPEZ DE CORSELAS, op. cit., 2009.

62 Cfr. M. PÉREZ GRANDE, op. cit., s.f. (2010), pp. 99-100, 103, 112 y 124-125. 
do con gran fortuna ${ }^{63}$. El conocimiento de ambos relicarios pudo despertar el interés de Albornoz por el círculo de plateros sieneses relacionados con dichas obras. En dicho contexto Petrucci actuó a modo de puente entre los mejores artífices sieneses de hacia 1330-1340 - con los que se formó- y el estancamiento del estilo posterior a $1350^{64}$. El relicario de la mano de Santa Lucía podría considerarse el "canto del cisne" de toda una tradición y al mismo tiempo iniciador de una tipología novedosa.

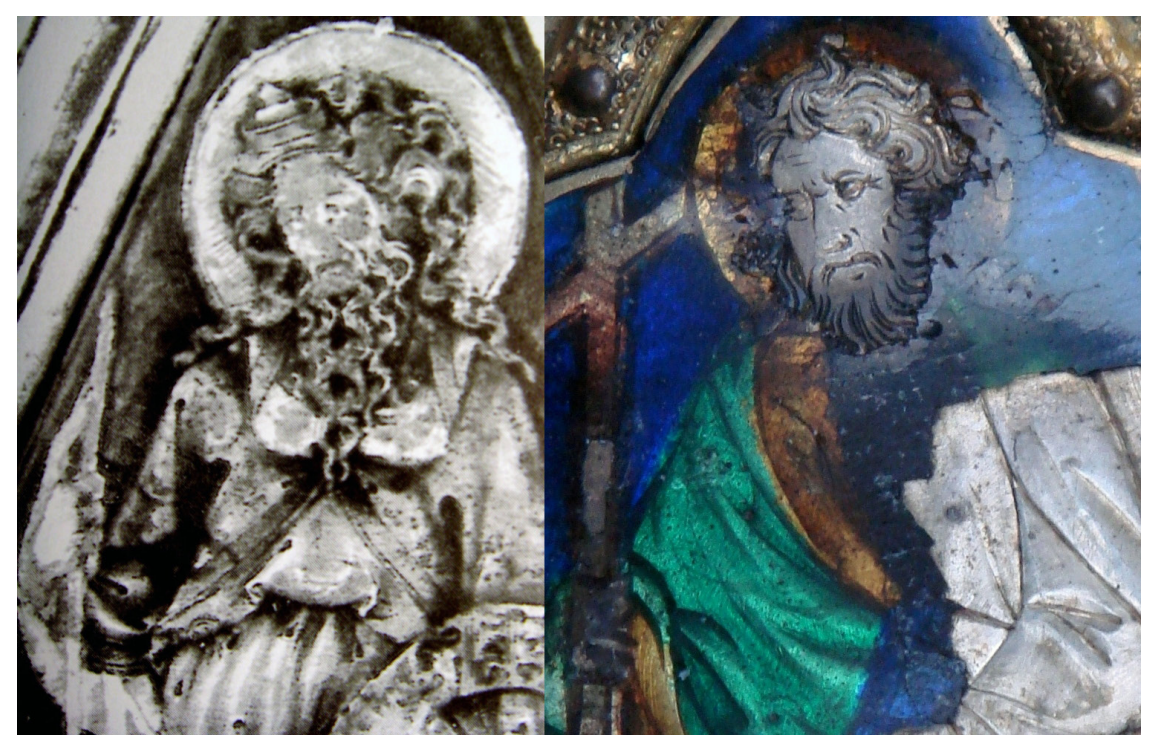

Fig. 5. A la izquierda, detalle del remate central de la cara posterior del relicario del Corporal de Bolsena (1338), firmado por Ugolino di Vieri y socios. Catedral de Orvieto; a la derecha, representación de san Andrés del cáliz de San Segundo (se ha invertido la imagen para su mejor comparación).

63 Sobre el asedio y otras visitas de D. Gil a Montefiascone, vid. la bibliografía citada en la nota 29.

64 E. CIONI LISERANI, “Appunti per una storia dell'oreficeria a Siena nella seconda metà del Trecento. La croce del Cleveland Museum of Art", A.C. QUINTAVALLE (ed.), Medioevo: arte e storia. Atti del X Convegno Internazionale di Studi, Milán, 2008, pp. 522-529. Estos cambios estilísticos que se detectan en los mencionados artífices responden al desarrollo general de la platería en la Siena del Trecento. Partiendo del legado de Guccio di Mannaia - autor del famoso cáliz de Nicolás IV (1288-1292)-, hacia 1320 la platería sienesa alcanzó su máximo desarrollo, manteniendo el nivel de creatividad y calidad durante al menos una década más. En los años 1340 se produjeron obras de alto nivel como el relicario de Santa Felicita de Montefiascone y el cáliz en la colección Martin D’Arcy (Loloya University Museum of Art), que continuaban la tradición de los primeros decenios del siglo, pero que además evidencian un acercamiento a los modelos pictóricos de la fructífera escuela sienesa, empleados tanto en los esmaltes como en la microescultura. La estudiosa añade que esta nueva situación se prolongó hasta la década de 1350, en la que se labraron obras de madurez - como el relicario de Toledo o la producción de Lippo Vanni- en las que los modelos pictóricos están plenamente asumidos. No obstante, fue difícil mantener el nivel de la producción, a lo que se sumaba el peso de la tradición gucciesca, difícilmente superable. A ello se añadieron factores de crisis como la peste de 1348 y sus consecuencias, que en el panorama de la platería favorecieron cierto estancamiento. Pese a que se acometieron obras tan excepcionales como el singular relicario de Toledo, los plateros supervivientes mantuvieron las técnicas asumidas - por ejemplo, hubo una revitalización del excavado- y se dedicaron más a la escultura que al esmalte. 


\section{Conclusiones}

El relicario de la mano de Santa Lucía preservado en la Catedral de Toledo estaba, como hemos visto, destinado a la capilla de San Ildefonso, aunque llegaría a Castilla desde el Colegio de España en Bolonia. Su origen y curiosa tipología están aún por aclarar, y esperamos contribuir en el futuro a despejar las dudas sobre el autor intelectual y la función original de tan valiosa pieza.

Respecto a su tipología, ¿quizás en origen la parte inferior y central de la pieza fueron diseñadas como parte de un relicario turriforme o incluso de un ostensorio, tal vez en la línea de las primeras custodias de asiento como la preservada en la Catedral de Ibiza? ${ }^{65}$ Existe otra pieza cuya función originaria se desconoce, y que coincide formalmente con la macolla y el pie del relicario de Santa Lucía. Se trata del curioso "Albero d'Oro" conservado en el Museo Comunale de Lucignano, en la provincia de Arezzo ${ }^{66}$. Es esta una desconcertante pieza, de origen sienés y, según su inscripción, comenzada en 1350 y completada en 1471. La macolla, perteneciente a la fase trecentista, es muy semejante en su morfología a la misma pieza del relicario conservado en Toledo. A la espera de poder profundizar en el posible vínculo entre ambas obras, en esta ocasión baste con señalar que las dos han sufrido alteraciones cruciales en su aspecto y función originales y que es factible que provengan del mismo contexto creativo y de mecenazgo, en el que destacarían como piezas clave en la experimentación tipológica característica del momento. Precisamente, en la región de Arezzo trabajaron artífices sieneses relacionados con el círculo de Ugolino di Vieri y de los Guerrino. Uno de ellos, posiblemente emparentado con estos últimos, fue Bartolomeo di Tondino, quien junto a Nello di Giovanni formó sociedad en Sansepolcro en $1372^{67}$.

Respecto a la autoría intelectual y la comitencia del relicario en Toledo, surgen varias posibilidades. El ciclo esmaltado de San Juan Bautista podría relacionarse con el ámbito en el que ejercían su mecenazgo la reina Juana I de Nápoles, así como el pontífice Juan XXII (†1334) y su sucesor Clemente VI (†1352), el cual obtuvo de la Reina la propiedad de Aviñón en 1352. Es asimismo interesante que bajo los pontificados de Clemente VI y de Inocencio VI († 1362) se decoraran tanto el Palacio Papal de Aviñón como la Cartuja de Villeneuve con escenas dedicadas a San Juan Bautista, obra de un pintor italiano, Matteo Giovannetti ${ }^{68}$.

Respecto a las circunstancias históricas de las piezas en estudio, hipotéticamente podemos sugerir que la reina Juana de Nápoles quedase prendada del busto-relicario

65 Para la custodia de Ibiza vid. N. DE DALMASES, L'Orfebreria Catalana Medieval: Barcelona 13001500, Barcelona, 1993, p. 113; F.X. TORRES PETERS, "La custodia de la Catedral de Santa María de Ibiza", J. RIVAS CARMONA (coord.), Estudios de platería. San Eloy 2010, Murcia, 2010, pp. 739-755.

66 Sobre esta obra vid. F. BARGAGLI PETRUCCI, Il reliquiario in forma d'albero a Lucignano di Val di Chiana, Siena, 1905; S. PICHI, “Il Trecento battezza l'arte orafa nell'Aretino”, A. GALLI y P. REFICE (eds.), Arte in terra d'Arezzo. Il Trecento, Florencia, 2005, pp. 237 y ss.

67 S. PICHI, op. cit., 2005, pp. 241-242.

68 Las similitudes entre las escenas de la Anunciación a Zacarías en la base del relicario de Santa Lucía y la representación mural en Villeneuve-lès-Avignon, ya las mencionó E. TABURET-DELAHAYE, op. cit., 1996-1998, p. 130. 
de San Blas que le entregó don Gil, o se trató simplemente de una valiosa donación que la reina necesitaba en aquellos momentos; en este caso Albornoz podría haber recurrido a este apreciado busto-relicario como regalo diplomático durante su esforzada legación, y cabe preguntarse si recibiría algo a cambio. En San Genaro se veneraba ya el busto-relicario del santo titular, y quizás la reina quiso ofrecer una donación personal a esta iglesia napolitana ${ }^{69}$. Claramente, el cardenal valoraba su relicario de San Blas, pues establecía en su testamento que debía ser llevado a Cuenca, junto con su preciada capa pluvial de Opus Anglicanum. El relicario de Santa Lucía, con su accidentada historia, así como el cáliz y la patena de San Segundo misteriosamente hallados en Ávila, están ligados en origen al mismo grupo de plateros sieneses, y estas tres piezas llegaron a España a través del círculo de don Gil de Albornoz, en el que tuvieron un papel clave su sobrino Fernando y su camarero Alonso, obispo de Ávila. Don Gil no solo se dotó de obras de gran valor crematístico e innovador, sino que además recurrió a algunos de los mejores artífices disponibles en la Italia del Trecento, como Andrea Petrucci, cuya actividad principal se situaría entre una posible formación en el contexto del relicario del Corporal de Bolsena (1338) y la finalización del relicario de la mano de Santa Lucía (como tarde, h. 1367); carecemos de evidencias precisas para datar los cálices de Ávila y Cambridge, aunque podrían situarse a mediados de siglo ${ }^{70}$. De cualquier modo, las obras más significativas de la orfebrería italiana del Trecento sienés conservadas en nuestro país se relacionan de forma directa o indirecta con el cardenal castellano. Don Gil de Albornoz se sitúa por tanto como mecenas y motor de novedades fundamentales en la platería, como lo fue asimismo en el derecho con sus Constituciones Egidianas o en la vida universitaria y en la arquitectura con su Colegio de España.

69 P. TOESCA, op. cit., 1951, p. 907.

70 El cáliz en el Museo Fitzwilliam de Cambridge presenta una corola que no es un añadido sino que forma parte de la obra original; esta pieza merece un estudio en profundidad. 